University of Nebraska - Lincoln

DigitalCommons@University of Nebraska - Lincoln

Publications, Agencies and Staff of the U.S.

Department of Commerce

U.S. Department of Commerce

2002

\title{
Estimation of Depth-Area Relationships using Radar-Rainfall Data
}

\author{
S. Rocky Durrans \\ University of Alabama \\ Lesley T. Julian \\ Carlin Brock University \\ Michael Yekta \\ National Weather Service
}

Follow this and additional works at: https://digitalcommons.unl.edu/usdeptcommercepub

Part of the Environmental Sciences Commons

Durrans, S. Rocky; Julian, Lesley T.; and Yekta, Michael, "Estimation of Depth-Area Relationships using Radar-Rainfall Data" (2002). Publications, Agencies and Staff of the U.S. Department of Commerce. 50. https://digitalcommons.unl.edu/usdeptcommercepub/50

This Article is brought to you for free and open access by the U.S. Department of Commerce at DigitalCommons@University of Nebraska - Lincoln. It has been accepted for inclusion in Publications, Agencies and Staff of the U.S. Department of Commerce by an authorized administrator of DigitalCommons@University of Nebraska - Lincoln. 


\title{
Estimation of Depth-Area Relationships using Radar-Rainfall Data
}

\author{
S. Rocky Durrans ${ }^{1}$; Lesley T. Julian²; and Michael Yekta ${ }^{3}$
}

\begin{abstract}
Depth-area relationships, such as those published by the National Weather Service in TP 40 and the NOAA Atlas 2 , enable conversion of point rainfall depths to areal average depths for the same storm duration and recurrence interval. This problem of conversion is most germane to hydrologic analyses for moderate to large drainage basins, where point rainfall depths are not representative of the spatial distribution of a storm event. Historically, depth-area relationships have been developed on the basis of data from dense networks of recording gauges. However, with the ongoing accumulation of radar-rainfall records, radar-rainfall data represent an alternative to gauging data. This paper summarizes what is believed to be the first study made under the auspices of the National Weather Service (NWS) for evaluation of the potential of NEXRAD radar-rainfall data for development of geographically fixed depth-area relationships. Objectives were to evaluate the use of radar-rainfall data for development of depth-area relationships and to identify potential obstacles that might hinder use of such data. Data analyzed for this study are those recorded for the Arkansas-Red Basin River Forecast Center (ABRFC), and span the period of time from May 1993, to September 2000. Conclusions of this study are that data heterogeneities and shortness of data records are major factors limiting development of depth-area relationships on the basis of radar-rainfall data. Possible biases in radar estimates of extreme rainfall are also of concern. Depth-area curves developed for the ABRFC, presented herein, are reasonably consistent with those presented in NWS publications but should only be considered as preliminary.
\end{abstract}

DOI: $10.1061 /(\mathrm{ASCE}) 1084-0699(2002) 7: 5(356)$

CE Database keywords: Hydrologic data; Rainfall; Data analysis; Arkansas.

\section{Introduction and Background}

Engineers and hydrologists, faced with the need to study relationships between precipitation and the resulting runoff from a drainage basin and with the need to design and manage water use and water control structures for the benefit and protection of mankind, require techniques whereby estimated point rainfall amounts can be transformed to represent an average rainfall amount over a specified area. The problem of point-to-area rainfall conversion may be addressed using depth-area curves, of which two types are usually recognized. The two types are commonly known as storm-centered and geographically fixed relationships and perhaps are best distinguished from one another by descriptions in U.S. Weather Bureau (1958a); U.S. Weather Bureau (1964); and Miller et al. (1973). A third approach to point-to-area rainfall conversion is known as the annual-maxima centered approach and has been presented by Asquith and Famiglietti (2000). This

\footnotetext{
${ }^{1}$ Associate Professor, Dept. of Civil and Environmental Engineering, Univ. of Alabama, Tuscaloosa, AL 35487. E-mail: rdurrans@coe.eng.ua.edu

${ }^{2}$ Consultant, 501 Tulip Ave., No. 3, Takoma Park, MD 20912. E-mail: lesleydipper@yahoo.com

${ }^{3}$ Computer Specialist, Hydrometeorological Design Studies Center, National Weather Service, Silver Spring, MD 20910. E-mail: michael.yekta@noaa.gov

Note. Discussion open until February 1, 2003. Separate discussions must be submitted for individual papers. To extend the closing date by one month, a written request must be filed with the ASCE Managing Editor. The manuscript for this paper was submitted for review and possible publication on June 20, 2001; approved on March 29, 2002. This paper is part of the Journal of Hydrologic Engineering, Vol. 7, No. 5, September 1, 2002. (CASCE, ISSN 1084-0699/2002/5$356-367367367 / \$ 8.00+\$ .50$ per page.
}

last approach to depth-area relationship development considers the spatial distribution of rainfall occurring concurrently with and surrounding an annual maximum at a point within the precipitation area.

Storm-centered relationships represent profiles of discrete storms and may be supported by data from sources such as the U.S. Army Corps of Engineers' historic storm rainfall atlases or by modern radar-rainfall data. For example, Dixon and Weiner (1993) document a software package known as TITAN, which can be used for storm tracking and development of stormcentered depth-area relationships. Storm-centered relationships are generally used in probable maximum flood studies, where there is a need to construct and/or transpose isohyetal patterns for estimation of probable maximum precipitation events. Those types of relationships are not discussed further here.

Geographically fixed depth-area relationships are estimated from averages of frequency-based quantile estimates using annual series of rainfall maxima observed at geographically fixed dense networks of gauges. The annual maxima at individual gauges seldom, if ever, occur during the same storm events, even when the gauges are closely spaced in a dense network. The net effect is that geographically fixed depth-area curves represent aggregated or composite, as opposed to individual, storm behaviors. In other words, a geographically fixed depth-area curve relates an average point rainfall depth, which may be determined from isopluvial maps for a fixed duration and return period, to an average areal rainfall depth for the same duration and return period. Because of this, geographically fixed depth-area relationships are generally used with information from precipitation-frequency studies.

It may be observed from this discussion that a geographicallyfixed depth-area reduction factor denoted by $\xi$ is defined as a 


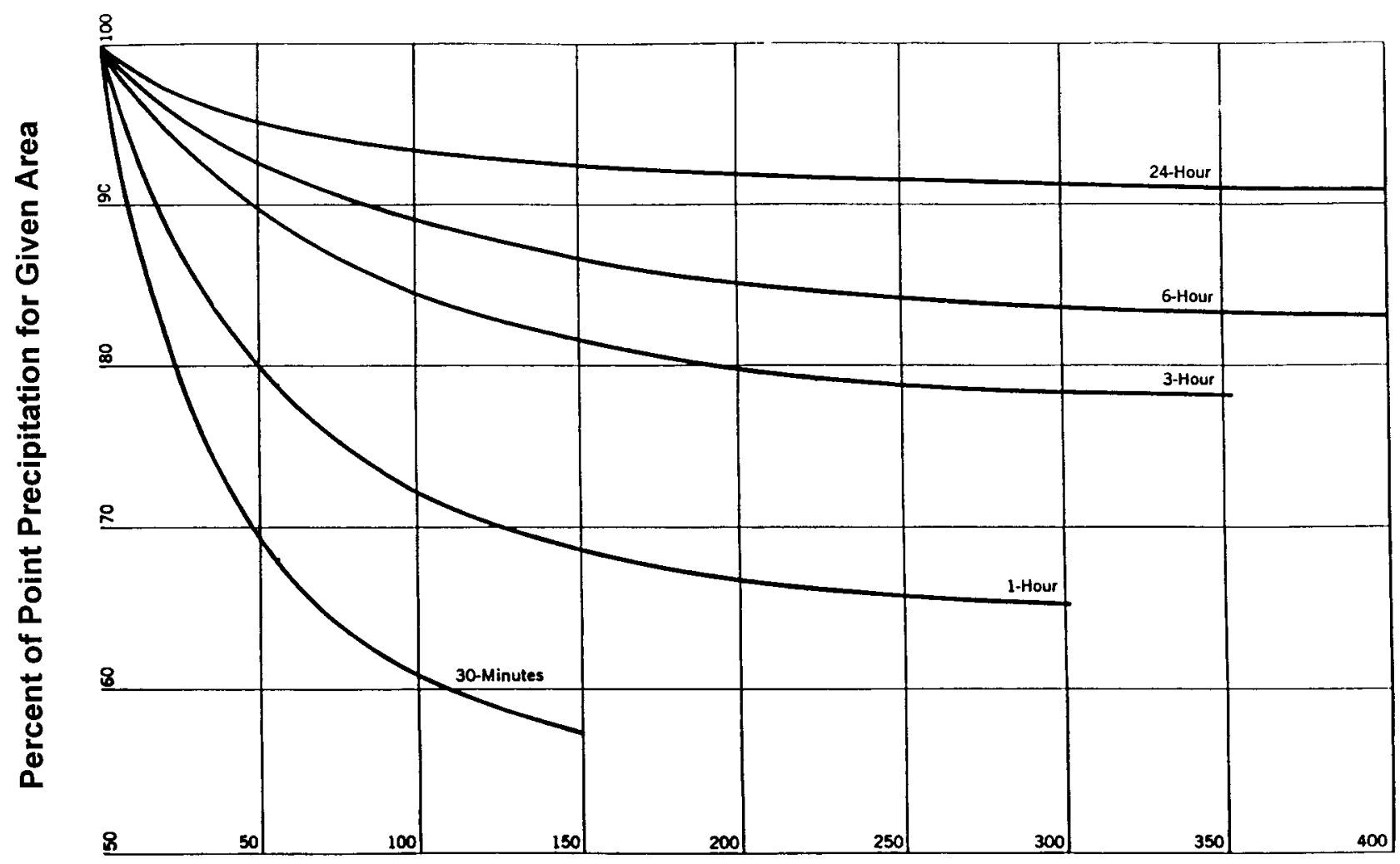

\section{Area (square miles)}

Fig. 1. Geographically fixed depth-area curves originally published by U.S. Weather Bureau in TP 29, Part 2 (U.S. Weather Bureau 1958a), and republished in subsequent official studies

ratio of two expectations. The numerator of the ratio is the spatially averaged depth $P_{A}$ of rainfall over an area $A$ corresponding to a particular storm duration $D$ and return period $T$. This spatially averaged depth may be written as $P_{A}(A, D, T)$. The denominator of the ratio is the arithmetic average of $n$ point estimates of rainfall, where each point estimate is made for the same duration and return period. Thus, the denominator can be written as $n^{-1} \sum P_{i}(D, T)$, and the depth-area reduction factor can be written as

$$
\xi(A, D, T)=\frac{P_{A}(A, D, T)}{n^{-1} \sum P_{i}(D, T)}
$$

A graph of the variation of $\xi$ with $A, D$, and $T$ is known as a set of depth-area curves or depth-area-duration (DAD) curves.

Estimates of the terms $P_{i}(D, T)$ appearing in Eq. (1) are usually obtained via frequency analyses of annual maximum series (as opposed to partial duration series) at individual rainfall gauging sites within an area of interest. In a similar vein, estimates of the numerator are also obtained from annual maximum series, where each element in the series is the maximum average rainfall depth over the area, conditioned on the requirement that all gauges in the area were simultaneously experiencing rainfall over the duration of interest. The effect of this simultaneity requirement is that $\xi \leqslant 1$ and $\xi=1$ only when $A=0$ (i.e., when the averaging area degenerates to a point). Qualitatively, when the storm duration is fixed, $\xi$ decreases with increases in $A$. For a fixed averaging area, $\xi$ increases as the storm duration increases. Fig. 1 is an illustration of the depth-area curves originally published by
U.S. Weather Bureau (1958a) and maintained in their original form since that time. Note that those depth-area curves are assumed to be independent of the storm return period.

The present study is exploratory in nature and represents what is believed to be the first effort taken under the auspices of the National Weather Service to address the issue of estimation of geographically fixed depth-area relationships using modern WSR88D (NEXRAD) radar-rainfall data. Radar-rainfall data, like gauge data, have limitations, but they represent a rich source of information that might be exploited to update previously published depth-area curves. Radar data provide information on the spatial coverage of rainfall that few dense gauging networks can match and appear to be uniquely suited to depth-area curve estimation needs. Further, radar data can be expected to become more reliable with the passage of time.

\section{Literature Review}

A summary of several important studies devoted to development of depth-area curves is provided in the following sections. The first section addresses "official" studies published by the National Weather Service and its predecessor the Weather Bureau. A second section addresses additional studies that have appeared in the archival literature. Because the present study deals with development of geographically fixed depth-area relationships, the summary focuses on developments of that type of relationship.

\section{Official Studies}

The U.S. Weather Bureau in 1957 published Part 1 of Technical Paper No 29 (TP 29) for the Ohio Valley (U.S. Weather Bureau 
1957). There, for the first time, depth-area analyses were completed and a set of curves were published. Depth-area reduction curves were developed for storm durations from $30 \mathrm{~min}$ to $24 \mathrm{~h}$, and for areas up to $1,024 \mathrm{~km}^{2}\left(400 \mathrm{mi}^{2}\right)$. Data used were from seven dense gauging networks located primarily in the eastern and central United States. General conclusions of the TP 29 Part 1 study were that the storm duration and averaging area were the major parameters affecting depth-area reduction factors. It was specifically noted that the curves seemed to be independent of geographic location, time of year, and other factors. It was tentatively accepted that storm magnitude (or return period) was not a parameter in the depth-area relationship, although it was noted that the records available were too short to evaluate the possible effects of this.

In Part 2 of TP 29 (U.S. Weather Bureau 1958a), data from additional dense gauging networks in the western United States were used to augment those in Part 1 . Nevertheless, the deptharea curves published in Part 2 were identical to those published earlier. Results of the analyses for the additional networks yielded no information to indicate that changes were necessary. The investigators did note a tendency for lower reduction factors for 1-h rainfall in regions with significant thunderstorm activity, as well as a slight tendency for a more uniform spatial distribution of rainfall in tropical storms than in nontropical storms; however, a lack of data, combined with the large amount of scatter present in the depth-area curves, led to retention of the original curves without modifications. In a similar vein, depth-area reduction curves published in Parts 3-5 of TP 29 (U.S. Weather Bureau 1958b, 1959, 1960), in TP 40 (Hershfield 1961), and the NOAA Atlas 2 (Miller et al. 1973) were identical to those published earlier in Parts 1 and 2. No changes were made to the curves in these later studies.

TP 49 (U.S. Weather Bureau 1964) extended the results of earlier studies to storms with durations up to 10 days. Using annual data series, estimates were made of the 2-, 5-, 10-, 25-, 50-, and 100-year depth-area reduction factors. However, comparisons of the depth-area curves for different storm return periods showed negligible differences (less than about 1\%), and it was judged that there was no need to publish separate curves for each return period. No regional variations were found in the analyses, although only limited parts of the country were examined. It was noted that the networks used were not adequate for delineation of regional variations, and the lack of any indicated regional variation was not conclusive.

Myers and Zehr (1980) report an approach to depth-area curve development emphasizing station-pair data. The model was developed and applied using data from a dense gauging network in the Chicago metropolitan area. The effects of return period on deptharea reduction factors were explicitly shown in figures included in the study. In particular, for a given storm duration and averaging area, lower depth-area reduction factors (i.e., smaller values of $\xi$ ) were found to be associated with long return period events than with short return period events. However, for storm durations of $24 \mathrm{~h}$ or more, the differences appeared to be negligible for practical purposes.

\section{Other Studies}

Roche (1963) conducted a theoretical study of the transformation of point-to-areal rainfall for isotropic random fields and presented a graphical approach by which the transformation could be made.

Rodríguez-Iturbe and Mejía (1974) also conducted a theoretical study of depth-area reduction factors assuming that rainfall fields are stationary and isotropic, and they have a correlation function that can be factored into spatial and temporal parts. Depth-area reduction curves were illustrated for two different types of spatial correlation structures (exponential and Bessel types). It was also pointed out that the geometric shape of the area in question has only a small influence on $\xi$, unless the shape is exceptionally elongated.

Frederick et al. (1977a), noting that digitized radar data offered an important new data source for defining depth-area curves, conducted a prototype study directed toward estimating geographically fixed depth-area reduction curves on the basis of digitized radar returns. It was noted that uncertainties in the $Z-R$ relationship used for converting radar reflectivities to rainfall rates are in part "divided out," because both the numerator and the denominator in the depth-area reduction factor [Eq. (1)] were estimated using radar data. A plot of depth-area curves computed using the radar data was presented in the paper (presumably for the 100-year return period, but this is not clear). On the same plot were shown the depth-area curves that had been published in TP 29 and subsequent "official" publications. Differences between the two sets of curves were marked, but it is not clear whether they are statistically significant because uncertainties in the curves were not shown (e.g., by scatters of data points).

Osborn et al. (1980) used records from the dense gauging networks in the Walnut Gulch (Arizona) and Alamogordo Creek (New Mexico) research watersheds to derive geographically fixed depth-area curves. Separate curves were developed for 2-, 10-, and 100-year return periods. Depth-area reduction factors developed for Walnut Gulch were significantly smaller than those published in official studies. Further, it was observed that there were greater differences between curves for different return periods than there were for curves for different durations. This stands in contrast to TP 29 and TP 49, where the storm duration appeared to be the most significant parameter. Depth-area curves based on the Alamogordo Creek data analyses are interesting in that $\xi$ values for long return periods are often higher than those for short return periods. The authors noted, however, that the differences are slight and may be due to sampling error. Another observation about the Alamogordo Creek $\xi$ values is that, although they generally are lower than those published by the Weather Bureau for most storm durations, they are higher than the Weather Bureau values for a storm duration of $30 \mathrm{~min}$.

Differences between the depth-area curves for Walnut Gulch and Alamogordo Creek and those curves published in official studies were attributed to differences in storm types. Storms producing annual maxima in Walnut Gulch tend to be pure air-mass thunderstorms covering very limited areas; therefore, depth-area reduction factors would be expected to be small. On the other hand, at Alamogordo Creek, large storms may be of the pure air-mass thunderstorm type, or they may be associated with a combination of frontal activity and convective heating, with the latter generally producing the annual maxima. The dense rain gauging networks studied in TP 29 did not represent the semiarid southwestern portion of the country for which the Osborn et al. (1980) work was completed.

Siriwardena and Weinmann (1996) studied depth-area relationships for Victoria, Australia. Relationships were developed for durations from 1 to 3 days for areas up to $8,000 \mathrm{~km}^{2}$ and for recurrence intervals from 2 to 100 years. The relationships were found to vary slightly with geographical location within Victoria, and reduction factors were found to be significantly lower than those presented in Australian Rainfall and Runoff (Institution of Engineers of Australia 1987). 
Asquith and Famiglietti (2000) developed annual-maxima centered depth-area relationships for Austin, Dallas, and Houston, Texas. As noted earlier, this approach to development of deptharea relationships considers the spatial distribution of precipitation concurrent with and surrounding a point annual maximum. It is therefore fundamentally different from other types of geographically fixed relationships in the sense that the recurrence interval associated with the areal rainfall is not specified or known. The recurrence interval associated with only one point in a rainfall area is known. Although the approach is interesting and is less computationally demanding than alternatives, the lack of knowledge of the return period associated with the spatially averaged rainfall depth may limit its practical application.

\section{Description of Radar-Rainfall Data}

Radar-derived rainfall data are collected by S-band Weather Surveillance Radar-1988 Doppler (WSR-88D) radars that have been deployed at over 160 sites throughout the United States. The first of these radars was deployed in 1991 and the last in 1997. Fully automated computer algorithms are used with the radars to generate hydrometeorological products. One of the algorithms, called the Precipitation Processing System (PPS), produces estimates of rainfall accumulations. A detailed description of the PPS is presented by Fulton et al. (1998).

The main digital rainfall product generated by the PPS is known as a digital precipitation array (DPA). A DPA is produced and updated every volume scan and is a running 1-h rainfall accumulation. Archives of "top-of-the-hour" DPAs can be used to assemble time series of sequential 1-h rainfall accumulations. Within a DPA, rainfall accumulations are mapped onto a polar stereographic projection called the Hydrologic Rainfall Analysis Project (HRAP) grid, which is a high-resolution grid nested into the limited fine mesh grid. The HRAP grid covers the coterminous 48 states and is nominally $4 \mathrm{~km}$ on a side. The grid size ranges from about $3.7 \mathrm{~km}$ at southern U.S. latitudes to about 4.4 $\mathrm{km}$ at northern U.S. latitudes.

NEXRAD hourly rainfall accumulations that are stored within individual DPAs may be combined with gauge data at NWS River Forecast Centers (RFCs) to develop multisensor rainfall estimates. The ways in which multisensor estimates have been developed and archived have evolved over time and are described by Young et al. (2000). The multisensor estimates can reflect a significant amount of human interaction, with forecasters at the RFCs being responsible for their assembly. Forecasters may decide to alter seemingly suspect gauge reports or to insert "pseudo gauges" and reports. Unfortunately, archives of alterations are not maintained; therefore, it is impossible to reconstruct the raw data products.

NEXRAD radar-rainfall products were provided for the present study by the NWS Hydrologic Research Laboratory (HRL). Data employed are multisensor estimates for the Arkansas-Red Basin RFC (ABRFC); those records are the longest and best documented of those presently available. Data extend over the time period from May 1993 to September 2000 and thus span about 7.5 years.

At the ABRFC, radar only data are merged with gauge only data and mosaicked to cover a $159 \times 335$ cell rectangle on the HRAP grid. The rectangle spans an area extending from eastern Colorado and New Mexico to western Arkansas in an east-west direction and from northeastern Texas to central Kansas in a north-south direction. Two types of multisensor products are archived for the ABRFC, but the archives do not specify which type of processing was used for any particular data file. Young et al. (2000) have estimated that the NWS Stage III methodology was used exclusively until about the summer of 1996 (but those authors also indicate that the biscan maximization option was turned off in February 1996). From 1997 forward, a Process 1 (P1) methodology developed by the Tulsa District of the Corps of Engineers has been used almost exclusively. During a transition period, both Stage III and P1 processing were used. Thus, data that have been archived and are employed in the present study are clearly heterogeneous. Nevertheless, these data represent the culmination of extensive development of the PPS and multisensor algorithms and represent the best data currently available.

\section{Data Limitations}

There are 46 adaptable parameters in the PPS that control its performance. Currently, most of the parameter settings are identical nationwide. Because of the general lack of experience with proper parameter settings for a particular locale, resulting rainfall data for that locale may be biased by improper settings.

Radar tilt angles may overshoot near-surface rainfall conditions, particularly in shallow stratiform rainfall events at ranges far from the radar. This can cause concentric discontinuities in derived rainfall fields. Discontinuities with spoke-like appearances can also arise as a consequence of transitions from one radar tilt angle to another. At far ranges, problems are also encountered with respect to incomplete beam filling and the typical reduction of reflectivity with increasing altitude.

The default $Z-R$ relationship currently used at most NEXRAD radar installations is given by the expression

$$
Z=300 R^{1.4}
$$

where $Z$ is the reflectivity $\left(\mathrm{mm}^{6} \mathrm{~m}^{-3}\right)$ and $R$ is the rainfall intensity $\left(\mathrm{mm} \mathrm{h}^{-1}\right)$. For some radar installations located in more tropical environments, an alternative expression is used instead. Battan (1973) provides a theoretical treatment of $Z-R$ relationship development and lists commonly observed parameter values as functions of storm type. In any case, the $Z-R$ relationship used at a NEXRAD installation is both temporally fixed and spatially uniform. Because the parameters are not optimized for each storm event, biases are almost sure to exist.

The $Z-R$ relationship can yield unreasonably large instantaneous rainfall intensities in some cases, particularly when some or all of the hydrometeors are in a frozen or mixed phase (e.g., hail or graupel). Because of these so-called bright-band effects, an adjustable hail cap threshold is used to place an upper bound on estimated rainfall intensities. The default value nationwide is 104 $\mathrm{mm} \mathrm{h}^{-1}$ but is often modified in tropical and dry environments. Nevertheless, in any study focusing on annual precipitation extremes, such as the present one, this cap could exert an adverse influence on estimated rainfall statistics.

Anomalous propagation of the radar beam, resulting in echoes from ground targets that may be misinterpreted as rainfall, can be caused by strong temperature and moisture gradients in the lower atmosphere. Clutter suppression and "tilt test" procedures have been designed to permit corrections for these effects, but these algorithms are most effective when anomalous propagation occurs in the absence of rainfall echoes. Improved algorithms are needed to address the situation when rainfall and anomalous propagation occur concurrently.

\section{Description of "Gauging Networks"}

Most previous studies dealing with development of geographically fixed depth-area relationships have made use of recording 

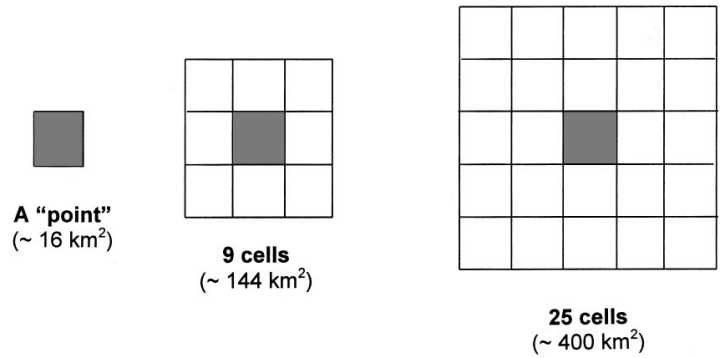

Fig. 2. Examples of square lattices used to represent gauging networks

gauge data available at a limited number of dense networks. In the present study, where radar-rainfall data are used instead, gauges are assumed to be represented by HRAP grid cells. That is, the volume-averaged hourly rainfall accumulation for each grid cell is assumed to be a point measurement. Of course, point rainfall is not truly represented because of the volume averaging that takes place in the PPS algorithms. Thus, at least from a theoretical point of view, depth-area relationships developed on the basis of radar data should be expected to be different from those based on point measurements at gauges.

Despite the theoretical distinction between gauge and radar estimates of rainfall, their differences are not believed to be significant for the practical purposes of development of geographically fixed depth-area relationships. To illustrate, the TP 29 deptharea curves (Fig. 1) yield a reduction factor of $\xi=0.95$ for a storm duration of $1 \mathrm{~h}$ and an averaging area of $16 \mathrm{~km}^{2}$ (equal to the nominal size of an HRAP grid cell). Values of $\xi$ even closer to unity are obtained for the longer durations of interest in this study. The closeness of these values to unity, and the underlying uncertainties both in Fig. 1 (see the TP 29 scatter plot from which the curves were developed) and in the estimates developed herein, lead to a conclusion that rainfall measured for a $16 \mathrm{~km}^{2} \mathrm{HRAP}$ grid cell can be practically considered a point measurement for the purposes of this study.

The square lattices shown in Fig. 2 represent progressively larger collections of HRAP grid cells, each of which contains a central cell. The number of cells in each collection varies as $N_{c}^{2}$, where $N_{c}$ is an odd integer $\left(N_{c}=1,3,5 \ldots\right)$. When $N_{c}=1$, there is clearly only one cell, and that cell is assumed to represent a point, even though its nominal area is $16 \mathrm{~km}^{2}$. When $N_{c}=3$, nine cells are represented for a nominal area of $144 \mathrm{~km}^{2}$, and so on.

As an example, the nine-cell configuration is assumed to represent a dense network of nine gauges for computation of deptharea ratios for an averaging of $144 \mathrm{~km}^{2}$ in this study. A similar assumption is made for the remaining configurations evaluated. The depth-area ratios computed for each configuration are assumed to be applicable to the geographical location of the shaded central cell, which could be any one of the cells in the HRAP grid. Table 1 summarizes the lattice arrangements used in this study for development of depth-area relationships.

\section{Data Analysis}

\section{Extraction of Annual Maxima}

Because of the large amounts of storage space consumed by the hourly data files, they were manipulated in 1-year sets. Files were stored for each hour in a calendar year (about 8,760 files, depend-
Table 1. Summary of Lattice Arrangements used as Gauging Networks

\begin{tabular}{lcc}
\hline$N_{c}$ & Grid cells represented & $\begin{array}{c}\text { Nominal area } \\
\left(\mathrm{km}^{2}\right)\end{array}$ \\
\hline 3 & 9 & 144 \\
5 & 25 & 400 \\
7 & 49 & 784 \\
9 & 81 & 1,296 \\
\hline
\end{tabular}

ing on whether data for the year were complete and whether the year was a leap year). Data for calendar years 1993 and 2000 were incomplete, but extremes extracted for those years were assumed to be annual maxima. This assumption was made to maximize the length of the resulting time series of data to $N=8$ years. Data for years 1994-1999 were very nearly complete, in fact, much more so than is typically the case with data files for individual rainfall gauges.

Extraction of annual maximum rainfall depths for each calendar year of record was accomplished for storm durations of 1, 2, and $4 \mathrm{~h}$ and for each of the $159 \times 335$ HRAP grid cells in the ABRFC region. Longer storm durations were not considered in this exploratory study because of time limitations and computational reasons.

Extraction of annual maxima of areal average rainfall amounts was accomplished for the same storm durations of 1,2 , and $4 \mathrm{~h}$, and for each of a set of $16 \times 33$ central grid cells representing the geographical locations of "dense gauging networks." The central cells defined for this purpose were positioned in an array of rows and columns spaced 10 grid cells in each direction. In the northsouth direction, where there are a total of 159 rows of grid cells in the ABRFC region, central cells were positioned in the 5th, 15th, 25 th, $\ldots, 155$ th rows. In the east-west direction, where there are a total of 335 columns of grid cells in the ABRFC region, central cells were positioned in the 8 th, 18th, 28th, ..., 228th columns. The arrangement of central cells is illustrated in Fig. 3.

The idea of using central cells as the centroids of $16 \times 33=528$ dense gauging networks stemmed from findings in the literature that depth-area relationships may vary significantly from one geographical region to another. The ABRFC spans a large region of the United States, with topography varying from the Great Plains to the Rocky Mountains. It was hoped that with the spatial density of radar-rainfall data one could begin to approach the problem of characterizing smooth spatial variations in depth-area curves (as opposed to having one set of curves for one geographical location and a distinctly different set of curves for another). As described in more detail later, statistical sampling variabilities caused by the short data records precluded this hope from becoming reality, although the concept should be able to be tested with longer data records when they become available.

For each central cell (i.e., for each dense gauging network) evaluated in the process of extraction of areal average annual maxima, it was required that all the surrounding cells (depending on $N_{c}$ and hence the averaging area) experience rainfall simultaneously over the storm duration of interest. This requirement is stated in the definition of the depth-area ratio [see Eq. (1) and the discussion below it] and is consistent with the way in which depth-area reduction factors have been computed in the NWS official studies. The areal average rainfall depth assigned to a central cell for a specified storm duration and averaging area was computed as the arithmetic average of the rainfall accumulations in each of the $N_{c}^{2}$ individual grid cells within the area. 


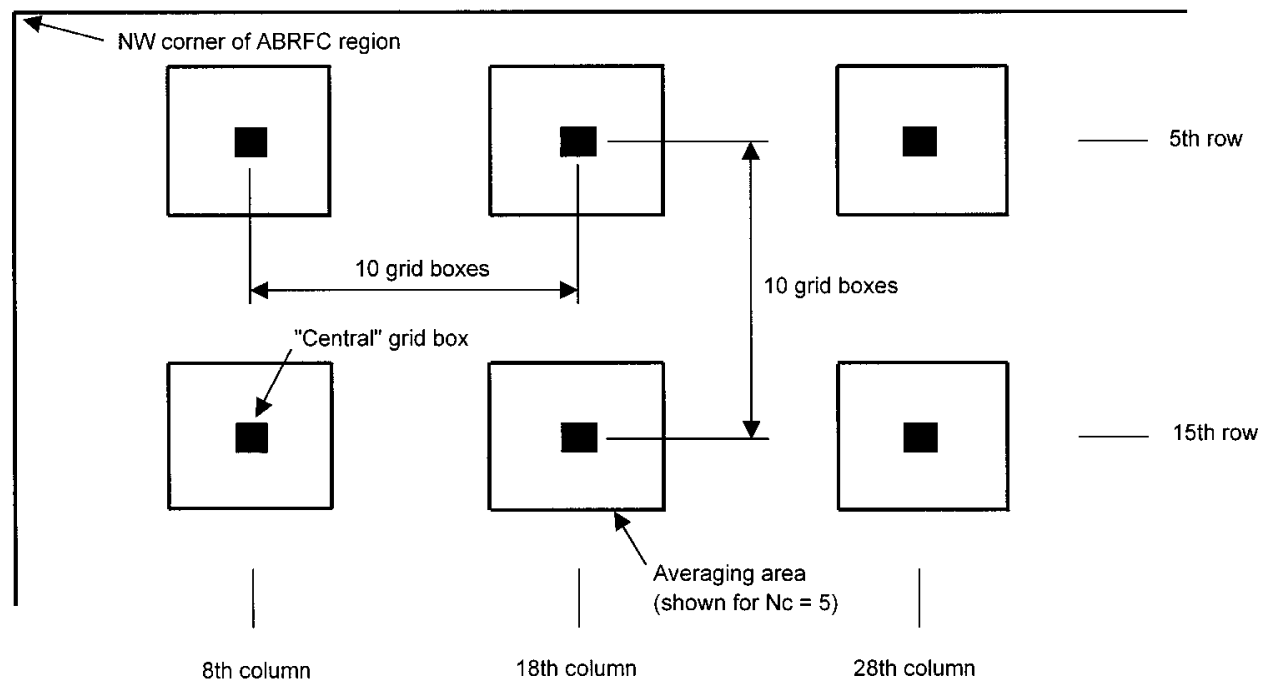

Fig. 3. Arrangement of "central cells" for which individual depth-area relationships have been developed

Time series of annual maxima extracted from raw data files exhibited apparent anomalies for calendar year 1997. In particular, maxima for that year were considerably larger than those for other years, in some cases by a factor of as much as 10 . For this reason, raw data for 1997 were examined in detail to identify those files containing one or more hourly rainfall depths in excess of $100 \mathrm{~mm}$. This threshold value was chosen somewhat arbitrarily, but is in excess of the 100-year, 1-h precipitation depth expected over any point in the ABRFC region (see Frederick et al. 1997b). Table 2 lists dates and hours associated with the identified files. Note that they are largely sequential, suggesting that some sort of contamination has occurred. Those files were eliminated from consideration, and annual rainfall maxima for 1997 were reextracted using the methods described above.

\section{Tests for Homogeneity and Stationarity}

The novelty of radar-rainfall data collection and archival (relative to older and more established gauging methods) means that archived records of radar data are usually quite short, and they may not be representative of long-term behavior. Further, because radar-rainfall processing algorithms have been under continuous development and refinement, the data that have been archived are heterogeneous as a consequence of modifications to the data processing algorithms. Statistical methods of data analysis assume that the data are homogeneous, and that they are representative of a temporally stationary random process.

Table 2. 1997 Data Files Identified as Containing Anomalous Data

\begin{tabular}{lc}
\hline Date $(\mathrm{s})$ & Hour $(\mathrm{s}) z$ time \\
\hline April 3 & 01 and 04 \\
June 5 & 01 \\
June 7 & $04-23$ \\
June $8-17$ & $00-23$ \\
June 18 & $00-12$ \\
June 25 & 02 \\
August 11 & 04 \\
August 12 & 06 \\
August 19 & 03 \\
\hline
\end{tabular}

The nonparametric Mann-Whitney test (Mann and Whitney 1947) has been used in this study to test the hypothesis of homogeneity. Testing was two-sided, and was performed at a significance level of $10 \%$. Testing was performed on time series of annual maxima for each of the $159 \times 335$ HRAP grid cells in the ABRFC region and for each of the storm durations of 1, 2, and 4 h. Based on the indications by Young et al. (2000), individual time series were divided into two sets for testing. The first set of data included those for calendar years 1993-1996, and the second set was for calendar years 1997-2000. Results of the testing are presented in Table 3, which shows the percentages of the 159 $\times 335=53,265$ grid cells for which the null hypothesis of homogeneity was rejected. The rejection rates are considerably larger than the $10 \%$ level at which the testing was conducted, indicating that identified heterogeneities may be significant. In all cases where testing led to rejection of the null hypothesis of homogeneity, it was determined that the 1997-2000 data were stochastically smaller than the 1993-1996 data. Locations of grid cells for which the null hypothesis was rejected appeared to exhibit no systematic patterns.

Tests for trends in this study have been performed using Spearman's $\rho$, as suggested by Daniels (1950). Testing was two-sided and was performed at a $10 \%$ significance level. Testing was performed on time series of annual maxima for each of the $159 \times 335$ grid cells in the ABRFC region and for each of the storm durations of 1,2, and $4 \mathrm{~h}$. Results of the testing are presented in Table 4 , which shows percentages of the 53,265 grid cells for which a trend was detected. Also shown in Table 4, for the cells where trends were identified, are the percentages of upward and downward trends. Despite the apparent tendency for upward trends (which is at odds with the results of the Mann-Whitney testing), overall trend identification rates shown in Table 4 are quite close

Table 3. Summary of Mann-Whitney Tests of Homogeneity

\begin{tabular}{lc}
\hline $\begin{array}{l}\text { Duration } \\
(\mathrm{h})\end{array}$ & $\begin{array}{c}\text { Rejection rate } \\
(\%)\end{array}$ \\
\hline 1 & 26.1 \\
2 & 24.1 \\
4 & 21.1 \\
\hline
\end{tabular}


Table 4. Summary of Spearman's $\rho$ Tests for Trends

\begin{tabular}{lccc}
\hline Duration (h) & $\begin{array}{c}\text { Percentage of } \\
\text { cells having a trend }\end{array}$ & $\begin{array}{c}\text { Percentage } \\
\text { upward trends }\end{array}$ & $\begin{array}{c}\text { Percentage } \\
\text { downward trends }\end{array}$ \\
\hline 1 & 10.4 & 63.9 & 36.1 \\
2 & 10.6 & 67.9 & 32.1 \\
4 & 9.9 & 74.0 & 26.0 \\
\hline
\end{tabular}

to the $10 \%$ level at which testing was performed. Because of this, it is believed that evidence for trends in the data is weak.

Despite some evidence that 1997-2000 data are stochastically smaller than those for 1993-1996 and the weaker but contradictory evidence for a larger percentage of upward trends than downward trends, statistical analyses of data reported in the remainder of this paper have been performed assuming these data are homogeneous and stationary. Because of natural climatic variability and the shortness of the time series available, tests of hypotheses such as those presented in the previous paragraphs are necessarily not very powerful. Much longer time series of data must be obtained before more definitive conclusions can be reached.

\section{L-Moments and Smoothing}

$L$-moments, like classical product-moments, are statistics that may be used to characterize the properties of populations and samples and were introduced by Hosking (1990). L-moments are preferable to product moments because they are based on linear combinations of order statistics. Because of this, they are less prone to the adverse effects of outliers and have smaller variances than do product moments. They also have sampling distributions that are much more Gaussian.

Sample $L$-moments of the extracted annual maxima of the radar-rainfall data were computed using the direct sample estimators presented by Wang (1996). The first and second $L$-moments were computed, as was the coefficient of $L$-variation. Higher order $L$-moments and $L$-moment ratios were not computed because of the shortness of the data series and because they are not needed for estimation of the parameters in the Gumbel distributional model.

An estimate of any statistic, such as the first $L$-moment or a quantile, on the basis of a short data record is attended by a considerable amount of uncertainty. Indeed, estimates of sample $L$-moments computed in this study for adjacent HRAP grid cells and for adjacent central cells used for representing areal rainfall were observed to vary greatly from one another. With long data records, one would expect estimates of sample statistics to vary smoothly and continuously over a spatial domain. This expectation is the basis for drawing of smooth isohyetal contours in precipitation frequency studies. Because of the large differences in sample statistics from one grid cell to another and because one should expect a continuous spatial variation in sample statistics, the estimates of sample $L$-moments were spatially smoothed to reduce the effects of sampling variations caused by the short time series available. Smoothing was performed for all three sample statistics computed from the data and for all durations and averaging areas considered. A total of five passes of the smoothing algorithm were applied. In the first pass, the raw sample statistics for each grid or central cell were smoothed. In subsequent passes, additional smoothing of previously smoothed values was performed. The choice of the number of passes applied was necessarily judgmental, but smoothing was performed with the intent of developing a continuous variation in the spatial field of estimates without suppressing (i.e., over-smoothing) regional variations.

The smoothing algorithm applied was a simple distanceweighted averaging procedure similar to those used in official NWS precipitation frequency studies. For any of the center 157 $\times 333$ cells in the overall ABRFC region or for any of the center $14 \times 31$ central cells used for areal averages, the smoothed value for the cell was computed as 0.5 times the unsmoothed value for that cell, plus 0.5 times the average of the unsmoothed values for the eight surrounding cells. For cells lying along the edges of the grids, the smoothed value for a cell was computed as 0.5 times its unsmoothed value, plus 0.5 times the average of the unsmoothed values for the five surrounding cells. For a cell lying in one of the four corners of each of the grids, the smoothed value for the cell was computed as 0.5 times its unsmoothed value, plus 0.5 times the average of the unsmoothed values for the three surrounding cells.

As will be noted later, application of the smoothing algorithm caused some of the cell values to be modified such that computed depth-area ratios, defined by Eq. (1), are sometimes greater than unity for some durations, averaging areas, and recurrence intervals. This problem tends to be localized at locations near the edges of the grid, where the smoothing algorithm cannot be expected to be very robust. Therefore, this is not viewed as a significant problem and should be able to be overcome by merging (mosaicking) data sets for different RFC regions. The benefits of the smoothing, in terms of reducing spatial variabilities in individual sample statistics, are believed to far outweigh the adverse consequences near grid boundaries.

\section{Distribution Selection}

As alluded to in the previous section, the Gumbel distribution has been employed in this study for modeling the annual maximum series of both grid cell and areally averaged precipitation depths. Selection of this distribution has not been justified by means of goodness-of-fit testing or by the use of $L$-moment ratio diagrams (Vogel and Fennessey 1993; Hosking and Wallis 1997). Reasons for its selection include the following:

1. It is a two-parameter distribution, with a constant coefficient of skewness equal to 1.14. Because of the shortness of the data time series $(N=8)$, selection of a three or higher parameter distribution was not felt to be advisable because of the risk of overfitting.

2. It probably has been the most widely used two-parameter distribution for rainfall frequency analyses. Virtually all of the official studies completed by the NWS employed this distribution, and the results of this study should be reasonably consistent with them.

Future work along the lines of that reported here, based on use of longer data time series, should devote more attention to the issue of distribution selection, particularly in view of the fact that most recent rainfall frequency studies are employing distributions other than the Gumbel (see Durrans and Brown 2001). However, as pointed out by Myers and Zehr (1980), the issue of distribution selection may not be as important for depth-area studies as it is for rainfall frequency studies because a dimensionless depth-area ratio may be insensitive to the distribution used as long as both the numerator and denominator are calculated using the same distribution. 


\section{Precipitation Frequency Estimates}

Using the Gumbel distribution, with its parameters estimated from spatially smoothed $L$-moments, estimates of the 2-year and 100 -year precipitation depths were made for each of the $159 \times 335$ grid cells in the ABRFC region and for each of the three storm durations of 1, 2, and $4 \mathrm{~h}$. Estimates for each grid cell were made independently and did not account for any spatial correlation effects. Regionalization of estimates was not performed, although the spatial smoothing applied to estimated sample $L$-moments effectively implements a form of regionalization.

It is recognized that the available data records are much too short to enable reliable estimates of 100-year precipitation depths to be made, but one objective of the study was to study whether return period should be included as a parameter in depth-area relationships. Estimated depths for 100-year events, while highly uncertain, were chosen so differences between those and 2-year estimates would be large, and hence would tend to highlight any return period effects.

Isopluvial maps illustrating rainfall frequency estimates have not been prepared on the basis of these estimates, primarily because visual inspection of the estimates shows them to be rather inconsistent with gauge-based rainfall depths published in TP 40 (Hershfield 1961) and HYDRO-35 (Frederick et al. 1997b). In particular, the radar-based estimates tend to be much lower than those presented in TP40 and HYDRO-35, with differences being on the order of at least $20-35 \%$. These percentage estimates were made by comparing estimated values near the center of the grid for the ABRFC region to corresponding TP 40 and HYDRO-35 estimates for west-central Oklahoma.

An explanation for the differences between radar- and gaugebased rainfall frequency estimates is not clear. Short data records and natural climate variability may be partly to blame. Problems may also lie with the radars or with the PPS processing algorithms because annual maximum precipitation values may be systematically biased downward by averaging or noise-reduction processes within the algorithms. Downward biases also may be caused by the volume averaging that is inherent in radar data. Future research should be directed to the isolation of the problem cause(s), and to the implementation of corrective measures.

\section{Estimated Depth-Area Relationships}

Based on the use of the smoothed sample $L$-moments and the Gumbel distribution, depth-area ratios defined by Eq. (1) have been computed for durations of 1,2 , and $4 \mathrm{~h}$ for each of the averaging areas shown in Table 1 and for storm recurrence intervals of 2, 10, 50, and 100 years. That is, for chosen values of the averaging area (i.e., of $N_{c}$ ), duration and return period, the numerator of Eq. (1) was computed as the $T$-year estimate of the areally averaged precipitation depth. The denominator was computed as the arithmetic average of the $N_{c}^{2}$ estimates of the $T$-year precipitation depth for each grid cell in the averaging area. These ratios were computed for the geographical locations of each of the $16 \times 33$ central cells used in the areal analyses. Because the 528 resulting geographically fixed depth-area relationships are too voluminous to report in their entirety, only a few examples of them are illustrated herein.

For presentation of example depth-area relationships, the geographical location to which a given graph applies is indexed by $(i, j)$ coordinates, with $i=1,2, \ldots 16$ and $j=1,2 \ldots 33$. The coordinate $(1,1)$ corresponds to the most northwesterly central cell in the ABRFC region; whereas, the coordinate $(16,33)$ corresponds to the most southeasterly central cell.

\section{Examples of Depth-Area Relationships for Fixed Durations}

Fig. 4 illustrates a depth-area relationship for coordinate $(1,1)$, for the 1-h storm duration (curves for durations other than $1 \mathrm{~h}$ are not shown in the figure to make it more readable). This represents a corner cell on the grid of central cells, and the edge effects of the smoothing algorithm are indicated by depth-area ratios greater than unity for some averaging areas and return periods. Also shown in the figure, for purposes of comparison, is the 1-h relationship from TP 29, Part 2 (U.S. Weather Bureau 1958a). The new curves yield higher $\xi$ values than does the TP 29 curve but should be held suspect because of the smoothing problems and the short data records used to compute them.

Fig. 5 illustrates the depth-area relationship for coordinate $(8,17)$, which is nearly centered in the ABRFC region. Again,

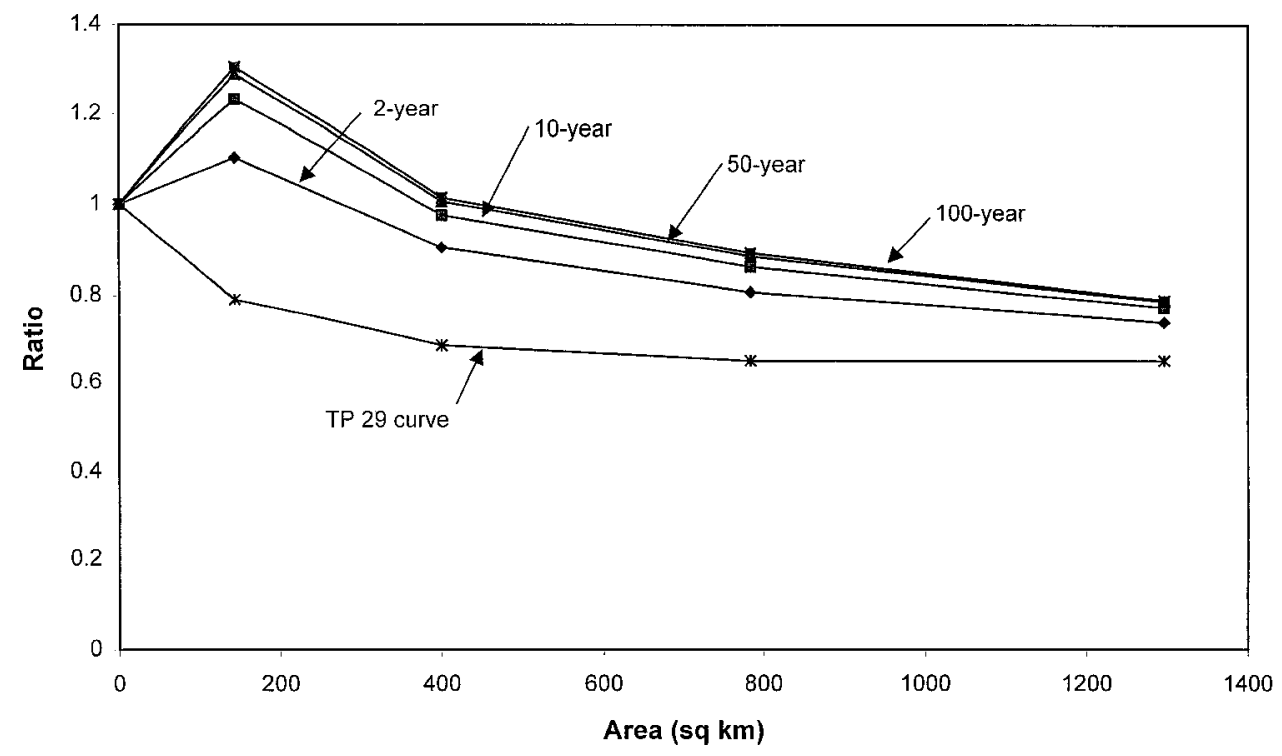

Fig. 4. Depth-area relationship for 1 -h storms at coordinate $(1,1)$ 


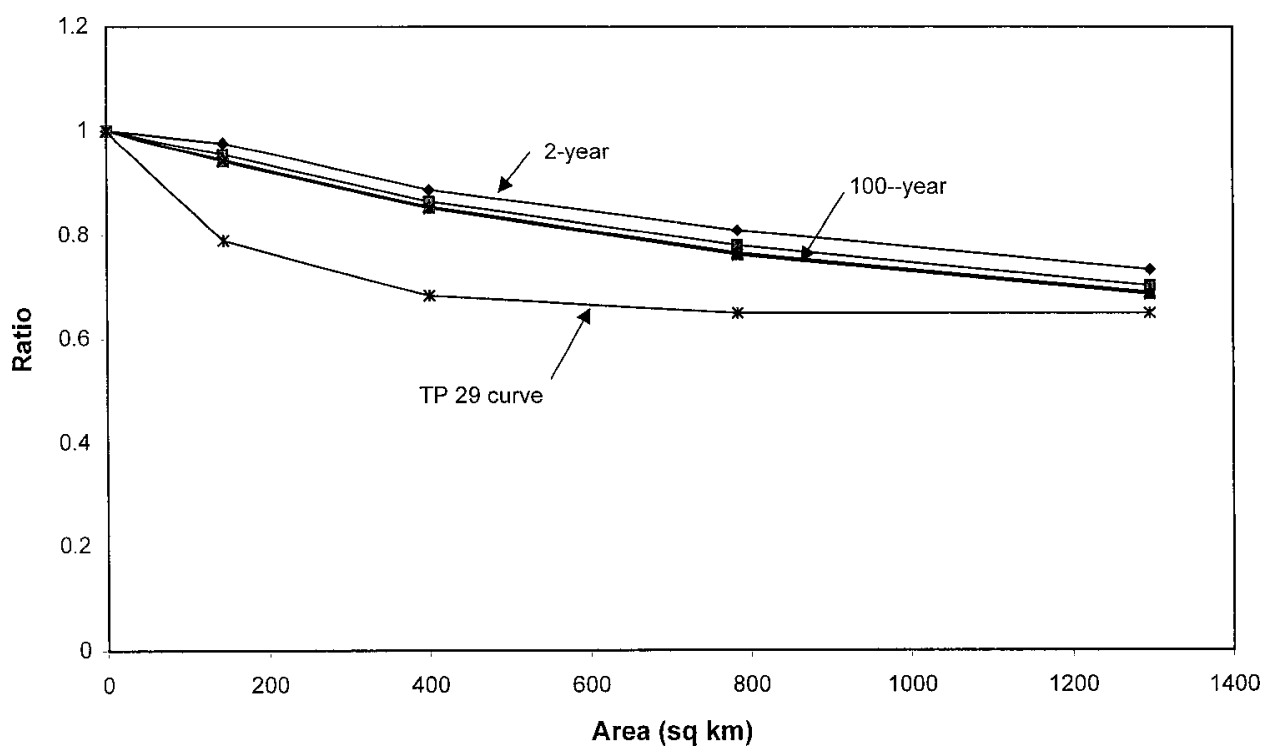

Fig. 5. Depth-area relationship for 1 -h storms at coordinate $(8,17)$

only the 1-h duration is shown. Depth-area ratios are all less than unity but are higher than those presented in TP 29. Curves shown for different storm return periods lie close to one another, showing that the depth-area ratio is rather insensitive to the return period. Note that the 100-year curve lies below the 2-year curve. Truly extreme events, such as the 100-year event, could be much more localized and thus have lower depth-area ratios than more frequent events. This behavior also could be due to sampling variabilities in the short data records.

\section{Examples of Depth-Area Relationships for Fixed Return Periods}

Fig. 6 is the depth-area relationship for the 2-year event at coordinate $(4,11)$. Shown are curves for each of the three storm durations of 1,2 , and $4 \mathrm{~h}$. The three curves lie quite close to one another, and even cross. This could be due to an insensitivity of the depth-area ratio to storm durations in this limited range from 1 to $4 \mathrm{~h}$, or it could be due to random sampling variations present in the short data time series, or both. Fig. 7 is a more reasonable relationship for the coordinate $(8,17)$, but the curves remain quite close to one another.

\section{Composite Depth-Area Curves}

As seen in Figs. 4-7, significant variability exists in depth-area curves estimated for different locations, despite attempts to smooth estimated sample statistics. Available radar-rainfall data records are simply too short to enable one to reliably identify geographical differences in depth-area relationships at this time. Because of this inability and because of the variability inherent in the estimated individual depth-area relationships, averaging of the relationships has been accomplished to develop composite deptharea relationships for the $\mathrm{ABRFC}$ region.

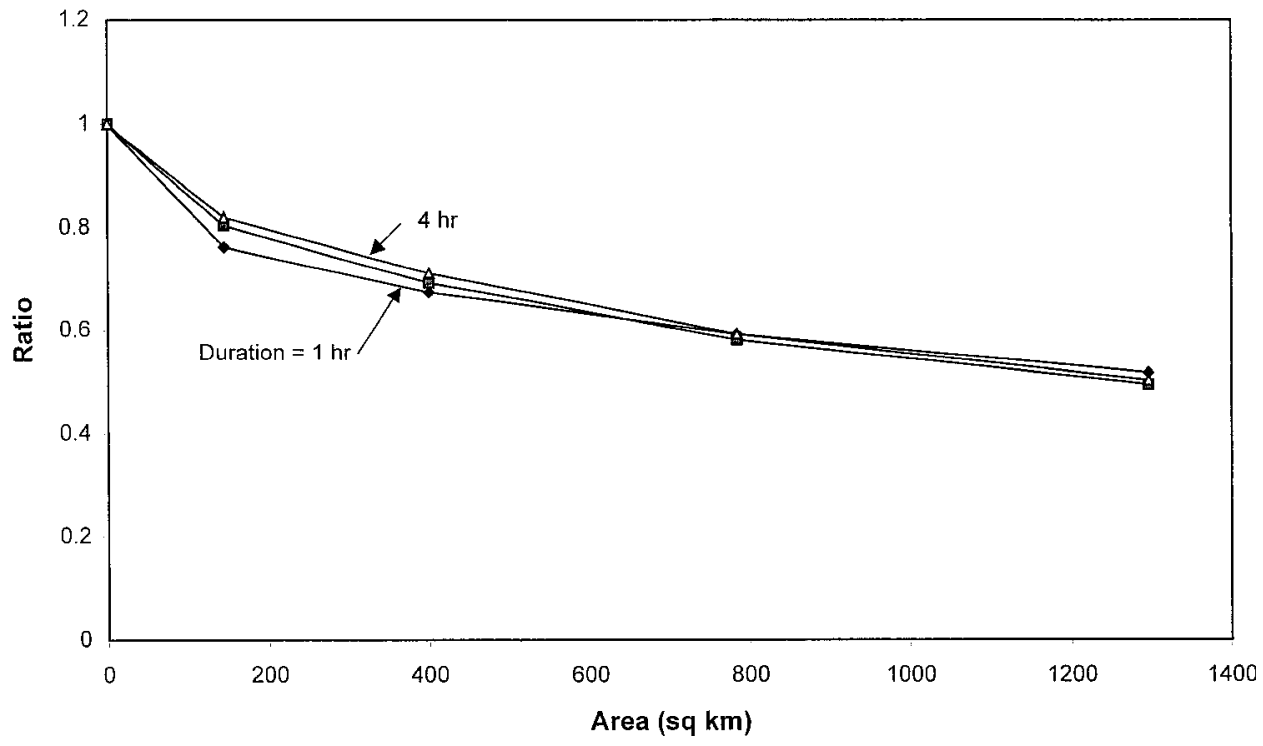

Fig. 6. Depth-area relationship for 2-year storms at coordinate $(4,11)$ 


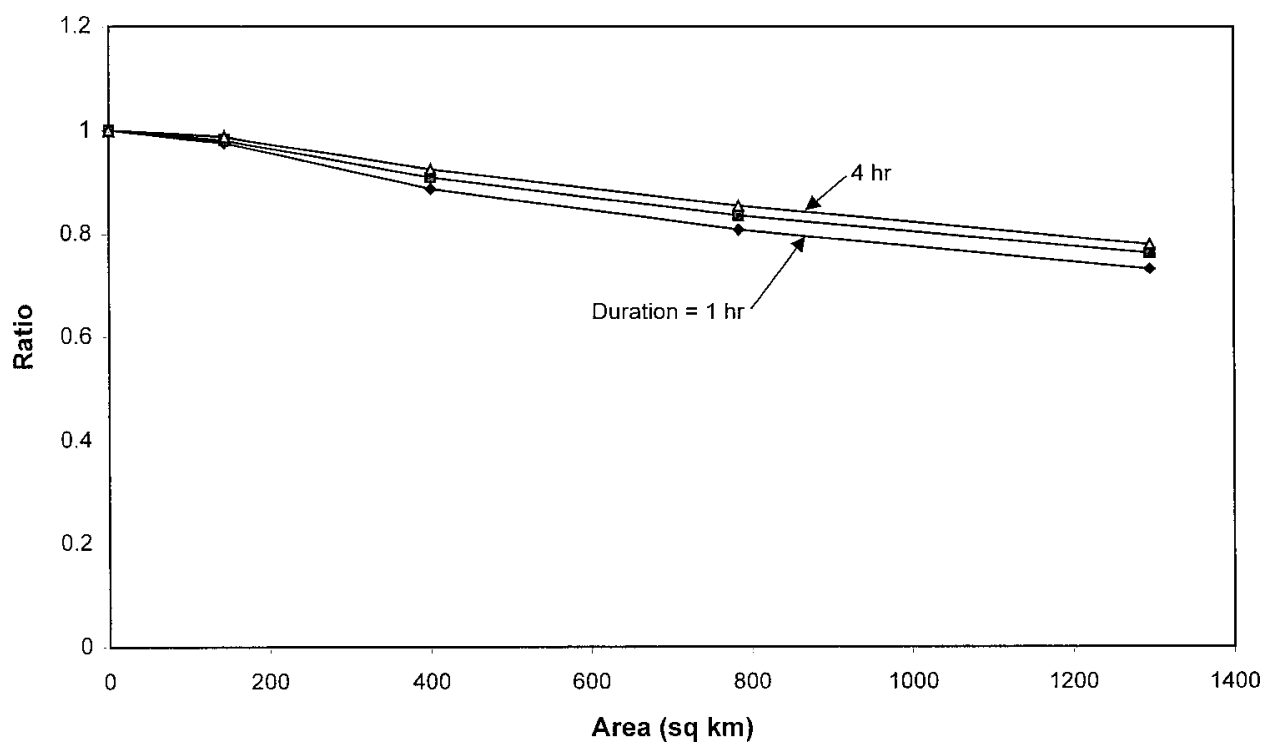

Fig. 7. Depth-area relationship for 2-year storms at coordinate $(8,17)$

Figs. 8 and 9 illustrate composite depth-area relationships for 2- and 100-year storms, respectively. The composite relationships are merely the arithmetic averages of the relationships developed for all of the central cells except those near the grid boundaries with $i=1$ or 16 and those with $j=1$ or 33 . A comparison of Figs. 8 and 9 shows that depth-area reduction factors are essentially independent of the storm recurrence interval; the curves for 2-year storms shown in Fig. 8 are essentially the same as those shown for 100-year storms in Fig. 9. The composite curves shown in Figs. 8 and 9 also show that depth-area reduction factors are rather insensitive to the storm duration, at least over the limited range of durations from 1 to $4 \mathrm{~h}$.

\section{Conclusion}

Because of the spatial coverages of rainfall fields that are provided by radar installations, radar-rainfall data appear to uniquely suited to applications involving developments of depth-area relationships. Few gauging networks are dense enough to provide the same degree of spatial detail. Development of depth-area relationships on the basis of radar-rainfall data is an exciting prospect for the future, but significant questions remain unresolved at present. The exploratory work presented herein has helped to identify some of the problems and questions inherent to the problem and should therefore be of use as guidance for future efforts.

Perhaps the most significant limitations of radar-rainfall data, both for frequency analyses and for development of depth-area relationships, are the shortness of the records and the heterogeneities caused by continual improvements to the data processing algorithms. These problems should disappear with the passage of time, but dealing with heterogeneities during further development of the processing algorithms may require archival of parallel, internally homogeneous databases. The shortness of currently available data records gives rise to large sampling variations in estimated statistics, with the net effect being that underlying

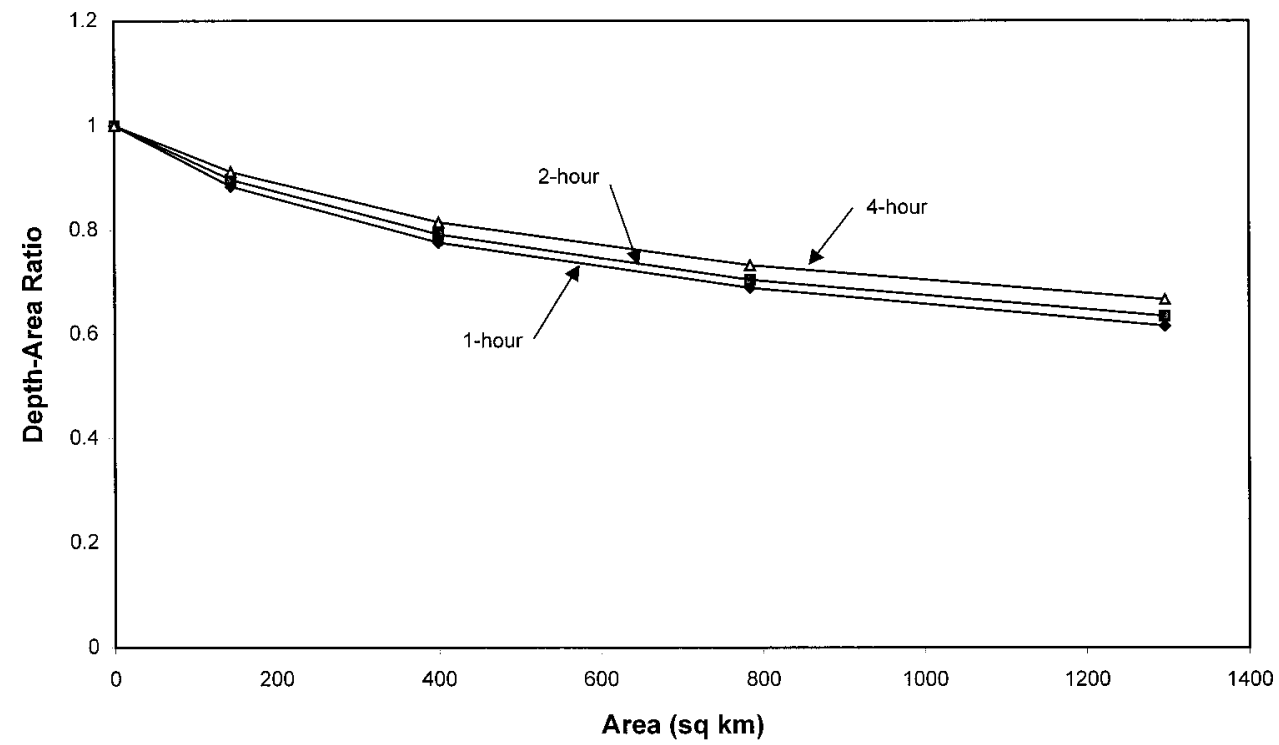

Fig. 8. Composite depth-area relationship for 2-year storms 


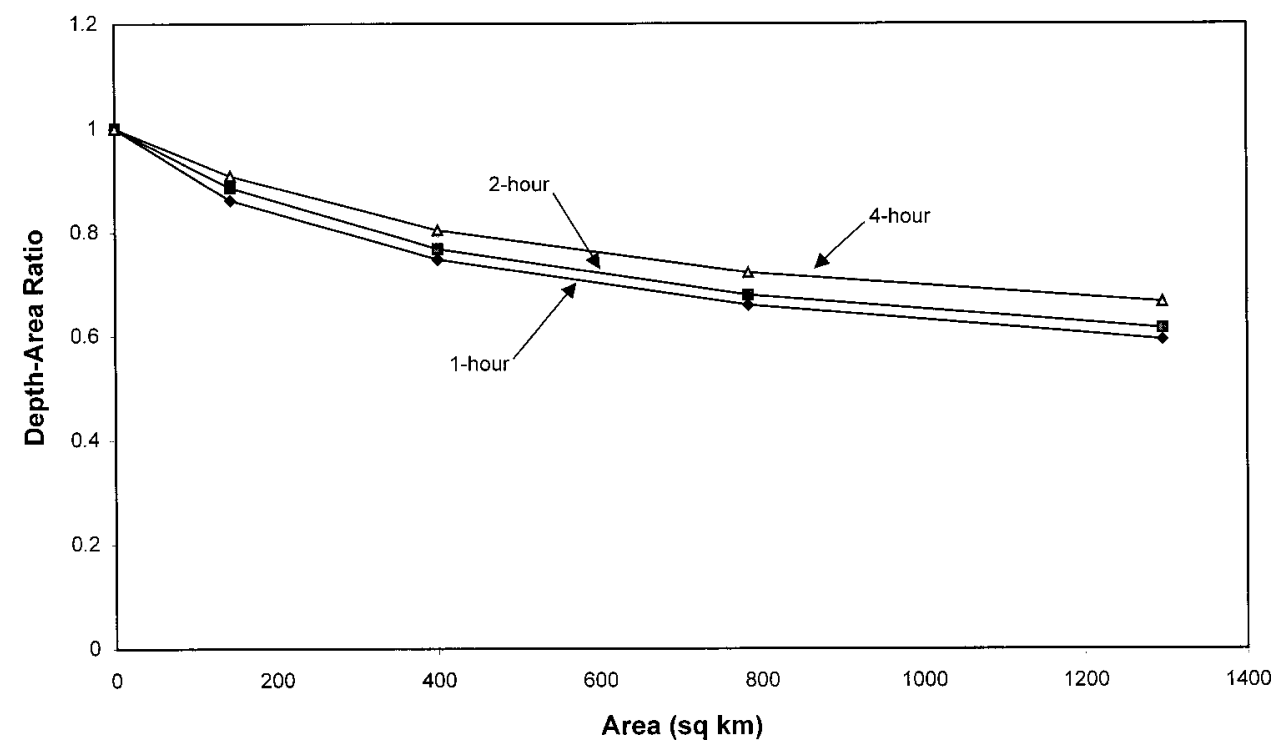

Fig. 9. Composite depth-area relationship for 100-year storms

relationships tend to be masked. Resulting rainfall frequency estimates and depth-area relationships are therefore uncertain and can display unreasonable and/or unanticipated characteristics.

Precipitation frequency estimates developed from radarrainfall data have been found to be significantly smaller than gauge-based estimates published in TP 40 and HYDRO-35, with differences being on the order of at least 20-35\%. Causes for these differences are not clear and could be due to either nonrepresentative data (due to short records and natural climate variability) or to characteristics of the radars and PPS processing algorithms.

Despite the differences between precipitation frequency estimates obtained using radar- and gauge-based data sources, estimates of depth-area ratios based on radar-rainfall data seem to be reasonably consistent with those published in TP 29, Part 2. Differences clearly exist but also should be expected. Depth-area curves represent dimensionless ratios of frequency estimates, with the net effect that errors present in each of the numerator and denominator of the ratio may tend to cancel out. Estimated deptharea relationships presented in this study display a significant amount of spatial variability, which is due largely to random sampling variations present in the short data time series used. Longer records should eliminate most of this variation. Merging (or mosaicking) of estimates for adjacent RFC regions should also eliminate estimation problems near grid boundaries. In sum, even though radar-rainfall data can support the development of deptharea relationships in concept, the significant uncertainties that remain indicate that the results presented herein can be considered as only preliminary. Much additional research is needed.

There are a number of directions that future research on this topic might take. For example, what are the effects, if any, of the hail cap threshold on estimated depth-area relationships? In a similar vein, what are the bright-band effects or the $Z-R$ relationship effects? Answers to questions such as these have not been able to be addressed in the present study because of time and resource limitations. They also have not been able to be studied because of problems that one would encounter in trying to reconstruct raw data from the archived multisensor databases. Continued research is necessary and should ultimately lead to significant improvements in estimates of precipitation frequencies and deptharea relationships.

\section{Acknowledgments}

This work was completed at the NWS Headquarters in Silver Spring, Md, during a sabbatical leave on the part of the first author. The support of the Office of Hydrologic Development and of the Universities Corporation for Atmospheric Research (UCAR) is gratefully acknowledged. Suggestions and comments by three referees led to clarifications and improvements in the manuscript.

\section{References}

Asquith, W. H., and Famiglietti, J. S. (2000). "Precipitation arealreduction factor estimation using an annual-maxima centered approach." J. Hydrol., 230, 55-69.

Battan, L. T. (1973). Radar observations of the atmosphere, Univ. of Chicago Press, Chicago.

Daniels, H. E. (1950). "Rank correlation and population models." J. R. Stat. Soc. Ser. B. Methodol., 12, 171-181.

Dixon, M., and Weiner, G. (1993). "TITAN: Thunderstorm identification, tracking, analysis, and nowcasting-A radar-based methodology." $J$. Atmos. Ocean. Technol., 10(6), 785-797.

Durrans, S. R., and Brown, P. A. (2001). "Estimation and internet-based dissemination of extreme rainfall information." Transp. Res. Rec., 1743, 41-48.

Frederick, R. H., Myers, V. A., and Auciello, E.P. (1977a). "Storm deptharea relations from digitized radar returns." Water Resour. Res., 13(3), 675-679.

Frederick, R. H., Myers, V. A., and Auciello, E. P. (1977b). "Five- to 60-minute precipitation frequency for the eastern and central United States," NOAA Tech. Memorandum NWS HDYRO-35, Office of Hydrology, National Weather Service, Silver Spring, Md.

Fulton, R. A., Breidenbach, J. P., Seo, D-J., Miller, D. A., and O’Bannon, T. (1998). "The WSR-88D rainfall algorithm." Weather and Forecasting 13, 377-395.

Hershfield, D. M. (1961). "Rainfall frequency atlas of the United States for durations from 30 minutes to 24 hours and return periods from 1 to 100 years." Tech. Paper No 40, U.S. Dept. of Commerce, Washington, D.C.

Hosking, J. R. M. (1990). " $L$-moments: Analysis and estimation of distributions using linear combinations of order statistics." J. R. Stat. Soc. Ser. B, 52(1), 105-124.

Hosking, J. R. M., and Wallis, J. R. (1997). Regional frequency analysis: An approach based on L-moments, Cambridge Univ. Press, New York. 
Institution of Engineers of Australia. (1987). Australian rainfall and runoff (ARR87), Vol. 1, Barton, Australia.

Mann, H. B., and Whitney, D. R. (1947). "On a test of whether one or two random variables is stochastically larger than the other." Ann. Math. Stat., 18, 50-60.

Miller, J. F., Frederick, R. H., and Tracey, R. J. (1973). Precipitationfrequency atlas of the western United States, NOAA Atlas 2, Vol. 1-11, National Weather Service, Silver Spring, Md.

Myers, V. A., and Zehr, R. M. (1980). "A methodology for point-to-area rainfall frequency ratios." NOAA Tech. Rep. NWS 24, Office of Hydrology, National Weather Service, Silver Spring, Md.

Osborn, H. B., Lane, L. J., and Myers, V. A. (1980). "Rainfall/watershed relationships for southwestern thunderstorms," Trans. ASAE, 82-87, 91.

Roche, M. (1963). Hydrologie de surface, Gauthier-Villars, Paris.

Rodríguez-Iturbe, I., and Mejía, J. M. (1974). "On the transformation of point rainfall to areal rainfall." Water Resour. Res. 10(4), 729-735.

Siriwardena, L., and Weinmann, P. E. (1996). "Development and testing of methodology to derive areal reduction factors for long duration rainfalls." Working Document 96/4. Cooperative Research Center for Catchment Hydrology, Monash Univ., Victoria, Australia.

U.S. Weather Bureau, (1957). "Rainfall intensity-frequency regime, Part 1-The Ohio Valley." Tech. Paper No 29, U.S. Dept. of Commerce, Washington, D.C.
U.S. Weather Bureau, (1958a). "Rainfall intensity-frequency regime, Part 2-Southeastern United States." Tech. Paper No. 29, U.S. Dept. of Commerce, Washington, D.C.

U.S. Weather Bureau, (1958b). "Rainfall intensity-frequency regime, Part 3-The Middle Atlantic region." Tech. Paper No. 29, U.S. Dept. of Commerce, Washington, D.C.

U.S. Weather Bureau. (1959). "Rainfall intensity-frequency regime, Part 4-Northeastern United States." Tech. Paper No. 29, U.S. Dept. of Commerce, Washington, D.C.

U.S. Weather Bureau. (1960). "Rainfall intensity-frequency regime, Part 5-Great Lakes region." Tech. Paper No. 29, U.S. Dept. of Commerce, Washington, D.C.

U.S. Weather Bureau. (1964). "Two- to ten-day precipitation for return periods of 2 to 100 years in the contiguous United States." Tech. Paper No 49, U.S. Dept. of Commerce, Washington, D.C.

Vogel, R. M., and Fennessey, N. M. (1993). " $L$ moment diagrams should replace product moment diagrams." Water Resour. Res., 29(6), 17451752.

Wang, Q. J. (1996). "Direct sample estimators of L moments." Water Resour. Res., 32(12), 3617-3619.

Young, C. B., Bradley, A. A., Krajewski, W. F., Kruger, A., and Morrissey, M. L. (2000). "Evaluating NEXRAD multisensor precipitation estimates for operational hydrologic forecasting." J. Hydrometeor., 1, 241-254. 